\title{
Trans-Septal Suture Technique to Stabilise the Middle Turbinate After Endoscopic Sinus Surgery
}

\author{
Salil Sood* and Deepak Gupta \\ Department of ENT, Great Western Hospital, Swindon, UK
}

Submission: June 19, 2018; Published: July 02, 2018

*Corresponding author: Salil Sood, ENT Fellow, Bradford Royal Infirmary, Bradford, UK, Tel: 07910562448; Email: Salilsood@hotmail.co.uk

\begin{abstract}
The middle turbinate is an important structure in Endoscopic sinus surgery. It ensures better identification of the nasal landmarks \& inadvertent damage to skull base. Over the years its importance, both structurally and functionally, has increased with the wider use of nasal endoscopes in the management of the sinoasal diseases. Postoperatively lateralization of the middle turbinate may cause scarring \& adhesions affecting the results of the surgery. A simple technique to stabilise the middle turbinate and prevent postoperative adhesions following the Endoscopic sinus surgery is described here. Although this was originally described in 1996 in America not many people are using it as it is considered technically difficult.
\end{abstract}

Keywords: Endoscopic sinus surgery; Middle turbinate; Trans-septal suture

Text

Equipment: Nasal Endoscope, 4/0 vicryl suture on $13 \mathrm{~mm}$ straight needle

Surgical technique: A simple method of putting a transeptal suture which results in medialization of middle turbinate and prevent adhesions and scarring between lateral wall and the turbinate.

Step 1: After endoscopic sinus surgery we take a 4/0polyglactin 910 (vicryl) suture on a $13 \mathrm{~mm}$ straight needle (Figure 1). Under endoscopic guidance it is passed through the middle turbinate in left nostril from the lateral to medial side (Figure 2) transversing the nasal septum to the contralateral side.

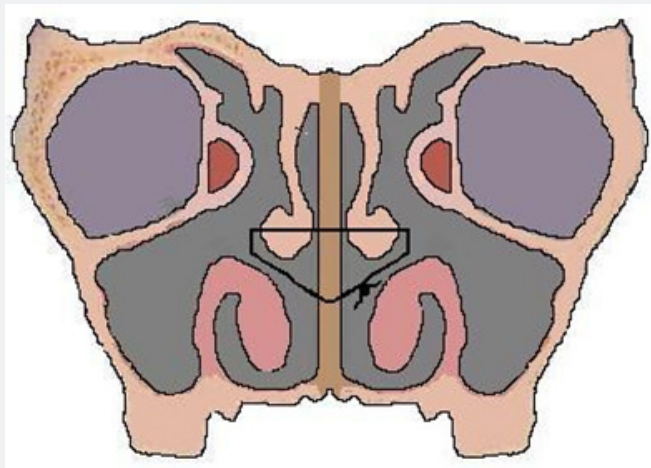

Figure 1: Schematic representation of the technique of Transeptal suture.

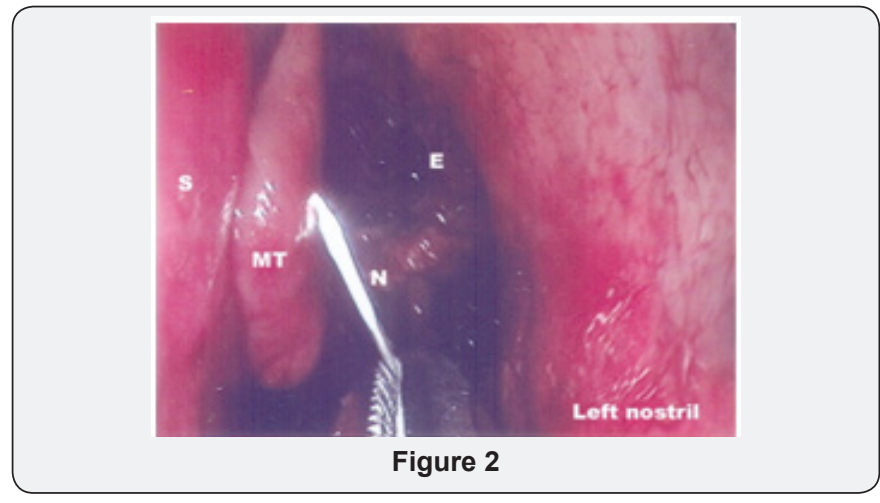

Step 2: The needle is continued through the middle turbinate from the medial to lateral on the other side and then brought out through the nose (Figure 3).

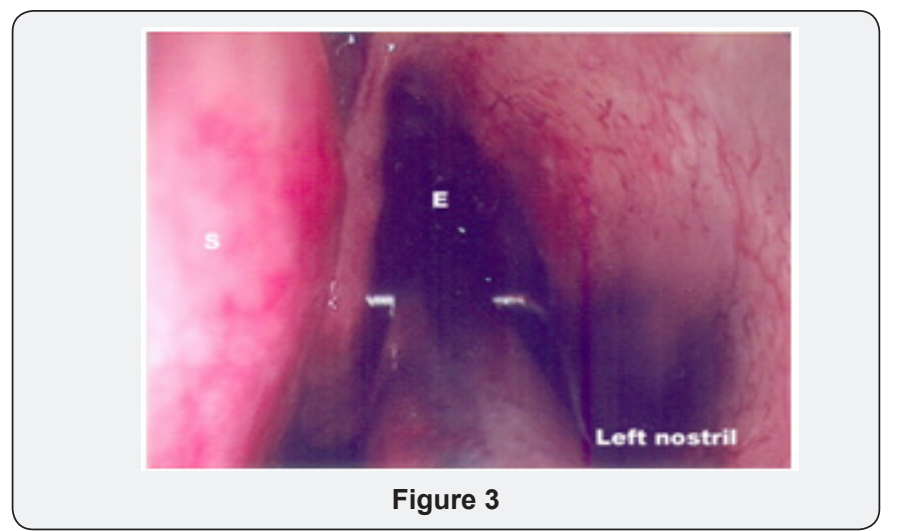




\section{Global Journal of Otolaryngology}

Step 3: The needle is picked up and it is then repassed in the opposite direction (Figure 4) just anterior to the anterior end of the middle turbinate through the septum (Figure 5) and knots are tied thereby securing the middle turbinate tightly against the septum (Figure 6).
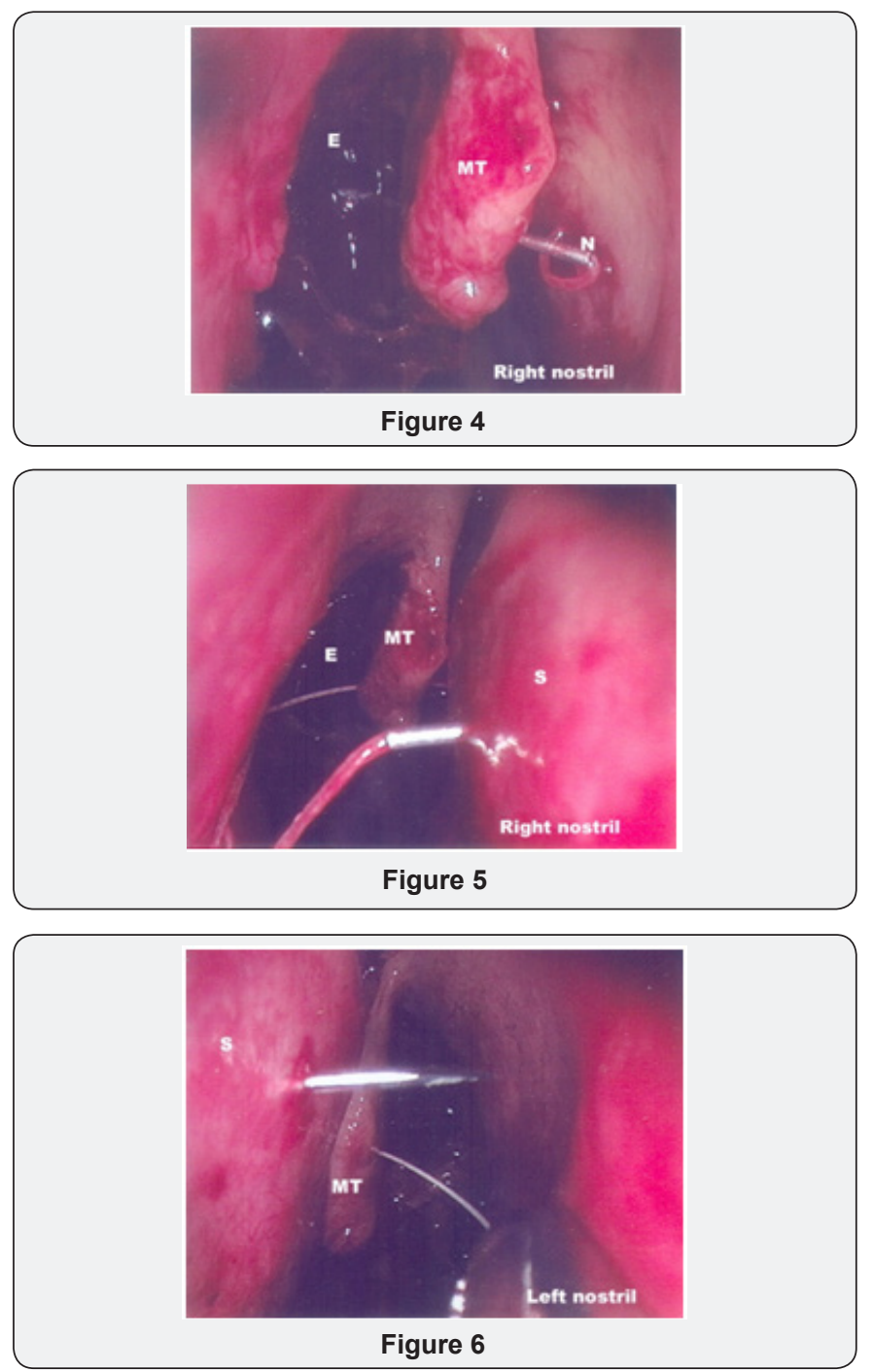

Step 4: The tightness of the knots is checked with an endoscope. The suture dissolves in around 4-6 weeks time thus medializing the middle turbinate without causing any further damage to the delicate sinonasal mucosa.

\section{Discussion}

The handling of the middle turbinate and prevention of lateralization appears to be the key to avoiding problems in the postoperative period. Some surgeons in the past have advocated partial or complete resection of the middle turbinate to prevent postoperative problems. The middle turbinate is an important landmark in the anatomy of the sinuses. Its presence ensures prevention of inadvertent damage to the base of the skull and easier identification of various structures during endoscopic sinus surgery. Medialization of the middle turbinate is vital to prevent obstruction of the ostiomeatal complex.
Polypoidal middle turbinate may restrict the passage of the nasal endoscope and prevent good view of the disease in the ostiomeatal complex. Although the best way to avoid adhesions and synchiae is to minimize damage to the delicate mucosa, at times this is unavoidable and at others some debridement of the middle turbinate may be necessary in order to access the ostiomeatal complex. Lateralizations of the middle turbinate and postoperative adhesions are the two most common causes for the poor results after endoscopic sinus surgery. This further causes therapeutic failures and necessitates revision surgery $[1,2]$. Thornton first described the technique of putting a transeptal suture to stabilize the middle turbinate in 1996 in a retrospective chart review of 31 patients [3]. For the reasons unknown this useful technique is not widely used as it is considered to be time consuming and technically difficult Figure 7.

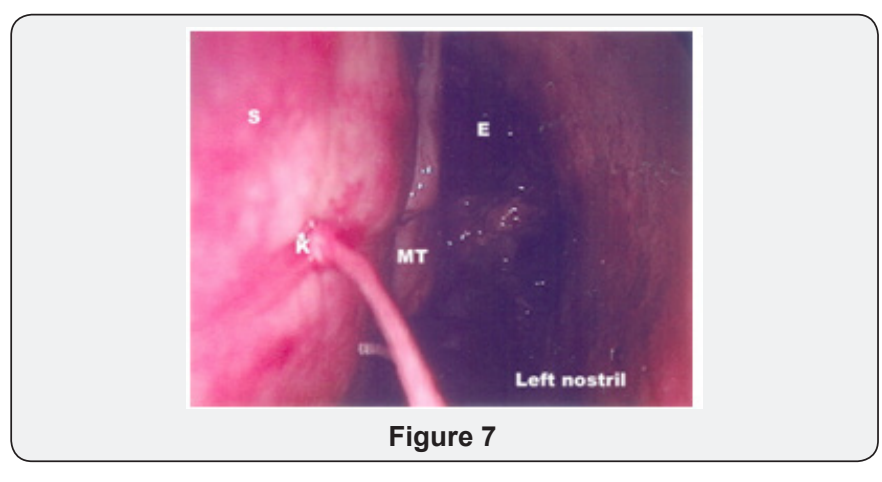

Over the years various techniques to ensure the medialization of middle turbinate have been in practice. Jabeles and Hick proposed placement of synthetic sponges in the middle meatus for extended period [4]. Shikani advocated the use of middle meatal antrostomy stent [5] whereas Brennan used the Boomrang turbinate glove [6]. All of these may cause foreign body reaction with resultant granulation tissue surrounding the stent and discomfort at the time of removal. W Bolger described the creation of an adhesion between the medial aspect of the MT and the nasal septum by abrading these surfaces using a sickle knife [7]. Freidman et al followed the same principle but using a microdebrider to create a raw surface [8]. Mourkarzel et al used surgical clips between middle turbinate and the septum [9]. However for "Bolgerization" to work a middle meatus stent has to be used to approximate the raw surfaces.

The Senior Author has been using this technique of placing a transeptal suture to medialize and stabilize the middle turbinate for the last 6 years. The suture is absorbable and avoids any long-term foreign body reaction. It avoids excessive granulation tissue as found with clips. It is more definitive and doesn't depend on healing of raw surfaces between the turbinate and the septum. Except for the original article by Thornton [1] we had not come across either anecdotally in literature any other reference to the use of this technique. However during the course of writing this paper we have come across the article by Bhalla et al. [10] al that described the suture technique with the first bite taken through the septum over the maxillary crest and then 
continued through the turbinate, we prefer to take the first bite through the turbinate and then continued through the septum. We have found the transeptal suture technique to be a good way of ensuring good postoperative results.

Adequate medialization of the middle turbinate:

i. Offers good view to the ostiomeatal complex during postoperative period:

ii. It is easier to remove crusts and inspection of the ethmoid complex

iii. The steroids drops or sprays can adequately reach the opened ethmoids cells.

iv. Aeration of the opened ethmoids is better as the middle turbinate doesn't get lateralized and block the OMC.

Adequate aeration is vital to the healing of the diseased nasal mucosa

\section{References}

1. Biedingmaier JD (1993) Endoscopic sinus surgery with middle turbinate resection: results and complications Ear nose throat J 72(5): 351-355.
2. Lzer RH, Younis RT, Long TE, et al. Revision functional Endonasal sinus surgery. Ear Nose Throat J 71(3): 131-133.

3. Robert S Thornton (1996) Middle turbinate stabilization technique in Endoscopic sinus surgery. Arch Otolaryngol Head Neck Surg 122(8): 869-872.

4. Jebeles JJ, Hicks JN (1993) The use of merocel for temporary medialization of the middle turbinate during functional endoscopic sinus surgery. Ear Nose Throat J 72(2): 145-146.

5. Shikani AH (1994) A new middle meatal antrostomy stent for functional endoscopic sinus surgery. Laryngoscope 104(5 Pt 1): 638-641.

6. Brennan LG (1996) Minimizing postoperative care and adhesions following endoscopic sinus surgery. Ear Nose Throat J 75(1): 45-48.

7. Bolger WE, Kuhn FA, Keenedy DW (1999) Middle turbinate stabilization after functional endoscopic sinus surgery. The controlled synechia technique. Laryngoscope 109(11): 1852-1853.

8. Friedman M, Landsberg R, Tanyeri H (2000) Middle turbinate medialization and preservation in endoscopic sinus surgery. Otolaryngol Head Neck Surg 123(1 Pt 1): 76-80.

9. Moukarzel N, Nehmé A, Mansour S, Yammine FG, Moukheiber A (2000) Middle Turbinate Medialization Technique in Functional Endoscopic Sinus Surgery. J Otolaryngol 29(3): 144-147.

10. Bhalla RK, Kaushik V, Carpentier de J (2005) Conchopexy suture to prevent middle turbinate lateralization and septal hematoma after endoscopic sinus surgery. Rhinology 43(2): 143-145.

\section{Your next submission with Juniper Publishers will reach you the below assets}

- Quality Editorial service

- Swift Peer Review

- Reprints availability

- E-prints Service

- Manuscript Podcast for convenient understanding

- Global attainment for your research

- Manuscript accessibility in different formats ( Pdf, E-pub, Full Text, Audio)

- Unceasing customer service

Track the below URL for one-step submission https://juniperpublishers.com/online-submission.php 